\title{
The effect of hormone therapy on quality of life and breast cancer risk after risk- reducing salpingo-oophorectomy: a systematic review
}

\author{
Tasneem Siyam¹, Sue Ross², Sandra Campbell ${ }^{3}$, Dean T. Eurich ${ }^{4}$ and Nesé Yuksel ${ }^{1^{*}}$
}

\begin{abstract}
Background: It is unclear if the use of hormone therapy $(H T)$ in carriers of BRCA mutations improves the quality of life (QOL) without increasing the risk of breast cancer following a risk-reducing salpingo-oophorectomy (RRSO). Our objective was to assess the effect of HT on QOL and breast cancer risk, after RRSO.

Methods: We searched MEDLINE, EMBASE, CINHAL, and others, from inception to July 22, 2016, to identify relevant studies. Two reviewers independently screened identified records for controlled trials and observational studies that addressed the effect of HT on QOL and breast cancer risk in women with BRCA mutations, post RRSO. Two reviewers independently extracted data on populations, interventions, comparators, outcomes, and methodological quality. Studies addressing the same outcome were synthesized using written evidence summaries or tables.

Results: Of the 1,059 records identified, 13 met our inclusion criteria. All studies were observational. Six studies assessed the effect on QOL. Of these, 3 showed improvement in QOL with HT use. The risk of breast cancer was evaluated in 4 studies. The mean duration of follow-up was 2.6 years (range 0.1-19.1). The risk of breast cancer did not change with HT use in all 4 studies.

Conclusions: Cumulative evidence from our review suggests that short-term HT use following RRSO improves QOL. The effect on breast cancer risk is still unclear. There are too few long-term studies to draw any strong conclusions. The need for future well-designed RCTs for more established evidence is imperative.
\end{abstract}

Keywords: Hormone Therapy, BRCA1/2, RRSO, Breast cancer, QOL

\section{Background}

BRCA mutations are associated with an increased risk of breast and ovarian cancer. In women with mutations of BRCA1 genes, the average cumulative risk for breast cancer by age 80 years is $67 \%$ and for ovarian cancer $45 \%$ [1-4]. In BRCA2 carriers, the average cumulative risks are $66 \%$ and $12 \%$, respectively [1-4]. Risk-reducing saplingo-oophorectomy (RRSO) offers reduction in the risk of ovarian cancer of approximately $80 \%$, among BRCA1 and 2 carriers, and of $50 \%$ for breast cancer [5].

\footnotetext{
* Correspondence: nese.yuksel@ualberta.ca

${ }^{1}$ Faculty of Pharmacy and Pharmaceutical Sciences, University of Alberta,

Edmonton, AB T6G 1C9, Canada

Full list of author information is available at the end of the article
}

However, more recent evidence suggests that breast cancer-risk reduction with RRSO may not be significant, particularly for BRCA1 carriers [6, 7]. Since cancer risk estimates for BRCA carriers are age-dependent and tend to be higher in younger age populations, [7] current guidelines recommend RRSO for BRCA carriers before age 40 years or after completion of child-bearing [8-11].

An immediate consequence of RRSO in premenopausal women is surgical menopause. Surgical menopause is associated with symptoms that can significantly affect a woman's quality of life (QOL), including vasomotor and urogenital symptoms, sexual dysfunction, sleep disturbances, and mood changes [12]. Furthermore, these women are at risk of long-term sequelae such as osteoporosis, cardiovascular diseases, and cognitive impairment 
[13-15]. In women with early menopause, who have no contraindications to hormone therapy (HT), current guidelines recommend the use of HT until the average age of menopause [16-18]. As BRCA mutation carriers would ideally undertake RRSO at an earlier age than women who perform it for other benign reasons or who go through early natural menopause, guidelines specific to BRCA mutation carriers suggest the consideration of short-term HT use due to the unknown nature of longterm safety [10].

The concern in women with BRCA mutations is that HT may further increase breast cancer risk following a RRSO. The Women's Health Initiative (WHI) randomized trials found an increased risk of breast cancer with estrogen plus progestin, although not with estrogen alone [19]. Data from short-term observational studies assessing the risk of breast cancer with HT use after RRSO are inconsistent, and at this time it is unclear if HT increases breast cancer risk following a RRSO [20, 21].

Carriers of BRCA mutations and women at high risk for breast cancer are often challenged by the decision to undertake RRSO due to the health consequences associated with surgical menopause, and the need for HT that may further increase their breast cancer risk. In 2014, Marchetti et al addressed this important topic in a narrative review, but the lack of details of the literature review method lead to concern about the rigor and completeness of the review [22]. Similarly, in early 2016, Birrer et al published a review of evidence about the safety of HT in women with BRCA mutations [23]. Even though they reported in their title and methods that they conducted a systematic review, the study lacked the main elements of a systematic review, such as a comprehensive literature search, an assessment of the methodological quality of studies included, and transparency in reporting the methods and findings [23].

We, therefore, performed a systematic review to assess the effect of HT on QOL and breast cancer risk in women who have BRCA mutations and who also underwent RRSO for breast and ovarian cancer-risk reduction. The effect of HT on other short and long-term outcomes was also evaluated.

\section{Methods}

Our study was designed and conducted in accordance with the guidelines for Meta-Analyses and Systematic Reviews of Observational Studies (MOOSE) [24].

\section{Eligibility criteria}

Eligible studies included women who had BRCA1/2 mutations or who had a high risk of breast and ovarian cancer (as defined by the original study authors) but had not undergone genetic testing, and who had undergone RRSO for cancer-risk reduction. Studies comparing the effect of HT (with no restriction on type, dose, regimen, or route of administration) to placebo, non-exposed group or baseline, qualified for inclusion. All controlled trials and observational studies (including prospective and retrospective cohort studies, case-control studies, and cross-sectional studies) were included. Review papers were screened for cited articles. Exclusion criteria included qualitative studies, hypothetical decision analysis, editorials and studies that did not assess the effect of HT on outcomes of interest. Studies that included women with a personal history of breast cancer were not explicitly excluded.

\section{Outcome measures}

Primary outcomes were QOL (general and menopausespecific) and breast cancer risk. Secondary outcomes included: vasomotor symptoms, vulvovaginal atrophy (VVA), sexual function, mood, sleep disturbance, bone loss, cardiovascular disease, stroke, venous thromboembolism, and mortality.

\section{Data sources and search strategy}

A systematic literature search was conducted by a librarian (SC) to identify all relevant published and unpublished studies. Searches using both controlled vocabulary and natural language were performed in databases including MEDLINE (1946 to March 7, 2016), EMBASE (1974 to March 7, 2016), and CINHAL (inception to March 7, 2016) (Additional file 1). Natural language search terms were derived from three main concepts: 1) RRSO, 2) BRCA mutations or high risk of breast and ovarian cancer, and 3) HT. Grey literature searches were conducted in SCOPUS, Web of Science, Google Scholar, Proquest, Dissertations and Theses and clinical trials registries, from inception to July 22, 2016 (Additional file 2). Other searches included hand searches of the reference list of review papers; and citation search of studies included in the systematic review. To increase the sensitivity of our search no language or date restrictions of publications were applied.

\section{Study selection}

Two-step screening for eligibility was performed independently by 2 reviewers (TS and NY), with disagreements resolved by consensus. First, titles and abstracts were screened to select articles eligible for further review. Second, full-text of relevant articles was reviewed for eligibility. Reviewer agreement for confirmation of eligibility was $100 \%$.

\section{Data extraction and quality assessment}

Data extraction was completed independently by two reviewers (TS, $\mathrm{AB}$ ), and discrepancies resolved by a third reviewer (NY). Data elements extracted included: manuscript characteristics; study design and settings; population characteristics; interventions; comparators; outcomes; and adjustments for potential confounders. The risk of bias 
assessment was conducted independently by two reviewers (TS, NY) and discrepancies resolved by consensus. The quality of studies was evaluated using the Jadad scale for RCTs, [25] and relevant versions of the Newcastle-Ottawa scale (NOS) for observational studies [26]. Cut off scores of $\geq 4$ for Jadad scale and $\geq 7$ for NOS were used to distinguish study quality [27]. Quality assessment scores were used to inform sensitivity analyses to evaluate its effect on pooled measure(s) of effect. Corresponding authors were contacted when data on outcomes were not available.

\section{Data synthesis}

Outcome data were synthesized by tabulating together all studies reported on specific outcomes. For each study, the outcomes reported were grouped by HT users versus nonusers, with mean differences or measures of association as relevant. Descriptive analysis was used for each outcome.

When sufficient homogeneity was demonstrated, outcome data were pooled quantitatively via a meta-analysis (as only two or three papers could be pooled for each outcome variable the details of the meta-analysis can be found in Additional file 3).

\section{Results}

Our search identified 1,059 records of which 51 full-text articles were retrieved and assessed for eligibility, and 13 were included (Fig. 1.) The most common reasons for exclusion are listed in Fig. 1. Additional file 4 lists all 51 studies reviewed for eligibility and the reason for exclusion whenever this may apply.

\section{Study characteristics}

Table 1 lists the main characteristics of the studies and their methodological quality. No RCTs were identified. The mean age of women across studies was 49.87 years (range 33-83), however, 6 studies did not report the participants' age [21, 28-32]. The mean age at RRSO surgery was 45.54 years (range 24-80). Studies included both BRCA1 and 2 carriers, except for 2, which included only BRCA 1 carriers $[21,31]$. In addition to BRCA mutation carriers, 6 studies included women who had high risk of breast and ovarian cancer with no confirmed genetic diagnosis $[29,32-36]$. Other variables, such as time since RRSO, body mass index (BMI), smoking status, history of breast cancer and hysterectomy were reported in some but not all studies. No studies included women with personal history of breast cancer. Intervention characteristics are listed in Table 2.

\section{Synthesis of results}

The outcomes reported for individual studies are shown in Table 3.

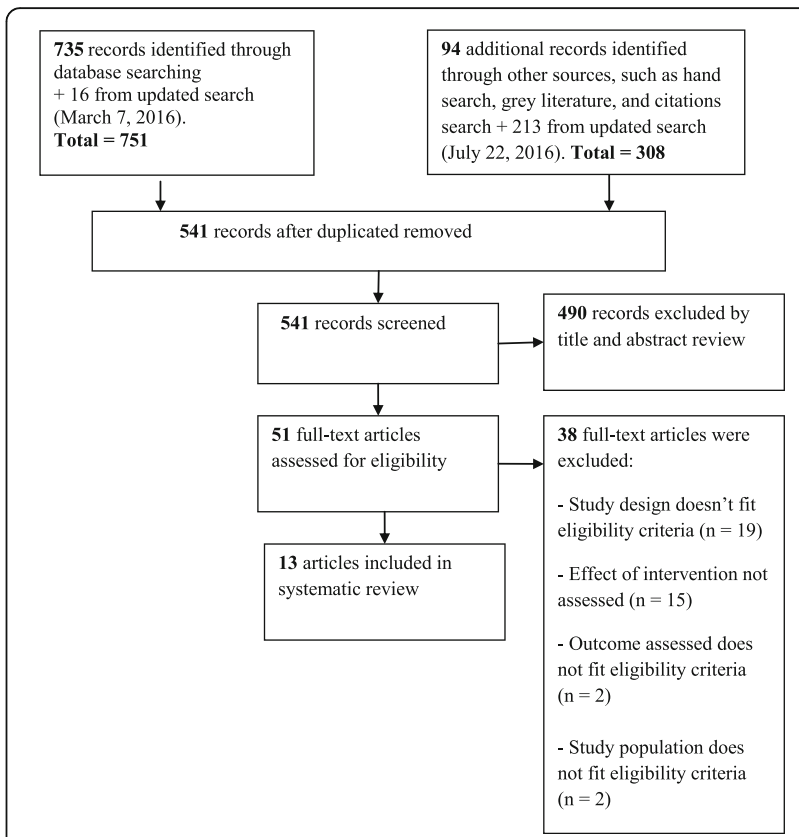

Fig. 1 Flow chart for study identification and selection

\section{Quality of life}

Six studies assessed the effect of HT on menopause-specific QOL [29, 32-34, 37, 38]. Tools of QOL assessment varied and included Functional Assessment of Cancer Therapy-Endocrine Score (FACT-ES) [33, 34]; Menopause Symptoms List (MSL) [37], Menopause-Specific Quality of Life-Intervention tool (MENQOL-I), [32, 38] and Menopause Rating Scale (MRS) [29]. Where reported, the mean age of women was 46 years or older in these studies [33, 34, 37, 38]. Studies differed with respect to the menopausal status at the time of RRSO surgery: 4 included pre and postmenopausal women, [29, 32, 37, 38] 2 included only pre-menopausal women [33, 34]. In one study including both pre and postmenopausal women, QOL was analyzed in the pre-menopausal group only [38]. Of the 6 studies evaluating QOL, 3 studies showed improvement in QOL, [32, 34, 38] and 3 showed no change [29, 33, 37]. One study evaluated the effect of HT on general QOL using the Short-form Health Survey (SF-36) [32]. The use of systemic HT improved only the pain domain of the SF-36 survey but none of the other domains.

\section{Breast cancer}

Four studies looked at breast cancer risk with HT use $[20,21,28,31]$. One study was an update of a previous analysis done by Eisen et al [21, 31]. All 4 studies included women, with confirmed BRCA mutations, of comparable mean age at the time of RRSO surgery and with no personal history of breast cancer. Two studies included BRCA1 and 2 mutations, with BRCA1 carriers, 


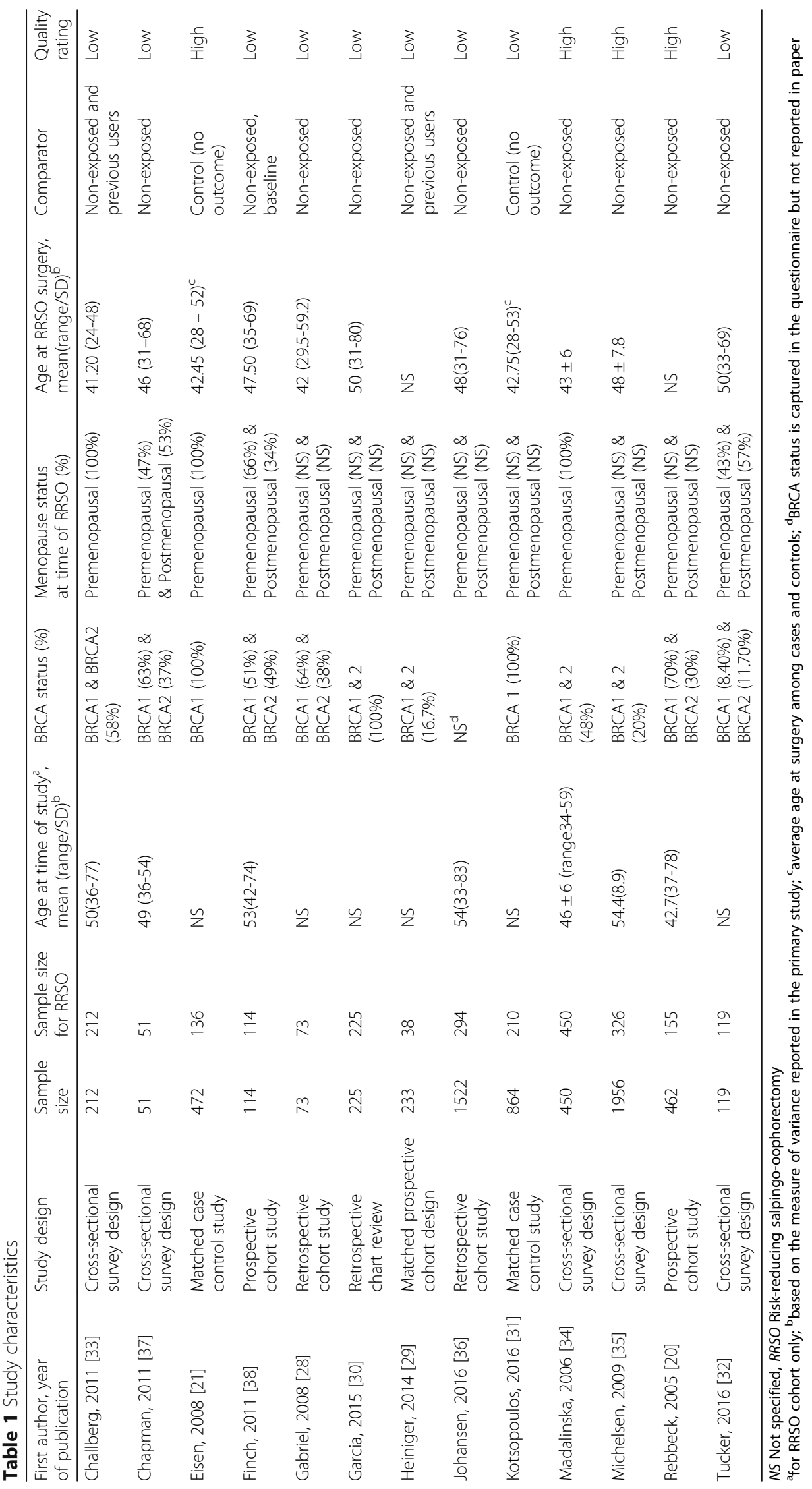


Table 2 Intervention characteristics

\begin{tabular}{lllll}
\hline First author & Type of HT & Dose of HT & Route of HT & $\begin{array}{l}\text { Duration of HTa-mean } \\
(\text { range/SD) }\end{array}$ \\
\hline Challberg [33] & ET, EPT and tibolone & NS & NS & $3.4(0.1-19)$ \\
Chapman [37] & NS & NS & NS & $6(0.75-9)$ \\
Eisen [21] & ET and EPT & NS & NS & $3.85^{c}$ (NS) \\
Finch [38] & ET and EPT & NS & NS & NS \\
Gabriel [28] & ET and EPT & NS & NS & $2.79 \pm 3.22$ \\
Garcia [30] & NS & NS & Systemic HT (60\%) & NS \\
Heiniger [29] & NS & NS & NS & NS \\
Johansen [36] & ET, EPT and tibolone & NS & Systemic HT (39.28\%) \& local/vaginal HT (6.54\%) & NS \\
Kotsopoulos [31] & ET and EPT & NS & NS & $4.35(0.05-25)^{c}$ \\
Madalinska [34] & EPT and tibolone & NS (standard) & Systemic HT (Oral/transdermal) & $3 \pm 2.3$ \\
Michelsen [35] & NS & NS & Systemic (Oral/transdermal) & NS \\
Rebbeck [20] & ET and EPT & NS & NS & NS \\
Tucker [32] & ET & NS & Systemic HT (20\% - oral and transdermal) \& local/vaginal HT (8\%) & NS
\end{tabular}

$H T$ hormone therapy, ET estrogen therapy, EPT estrogen-progestogen therapy, NS not specified

${ }^{a}$ in years; ${ }^{b}$ based on the measure of variance reported in the primary study; ' average duration of use among cases and controls

represented $\geq 60 \%$ in both $[20,28]$. The remaining 2 studies included only BRCA1 carriers [21,31]. All studies included ET and EPT users. The mean duration of HT use was 3.83 years (range 0.05-25). The mean duration of follow-up for the only prospective study was 2.6 years (range 0.1-19.1) [20]. Breast cancer risk did not change with HT use in any of the 4 studies.

Only 2 studies reported the effect of HT regimen on breast cancer risk [20, 28]. In Gabriel et al, 3 women on ET developed breast cancer (OR 0.48; 95\% CI, 0.1-2.1), with no cases in women on EPT [28]. Rebbeck et al. reported that compared to ET users the risk of breast cancer with EPT was higher but not significant (HR 2.56; 95\% CI, 0.08-78.13) [20]. The effect of HT duration of use on breast cancer was reported in one study [31]. Compared to never use, breast cancer risk did not change with greater than 3 years of HT use post RRSO.

\section{Other outcomes}

\section{Vasomotor symptoms}

Vasomotor symptoms were assessed in 4 studies [32-34, 38]. HT reduced the prevalence and/or severity of hot flashes in all studies.

\section{Sexual function}

Sexual function was measured in 5 studies as part of the QOL instruments (MENQOL, and FACT-ES), or using the Sexual Activity Questionnaire (SAQ), Female Sexual Function index (FSFI) or Female Sexual Distress Scale revised (FSDS) [29, 32, 34, 36, 38]. Two studies showed an improvement in sexual function with HT, using the sexual domain of MENQOL (Table 3) [32, 38]. The only aspect of sexual activity that consistently improved with
HT use across studies was discomfort/pain [32, 36, 38]. Other aspects of sexual activity, such as pleasure, habit, satisfaction and libido showed no improvement.

\section{Vulvovaginal Atrophy (VVA)}

Four studies measured the effect on VVA [32-34, 38]. In 2 studies, vaginal dryness was included as a component of sexual function: taking HT improved vaginal dryness and lubrication difficulty with intercourse $[32,38]$. Two studies measured the effect of taking HT on VVA, separate from sexual function, and did not find improvement $[33,34]$.

\section{Prevention of bone loss}

Three studies evaluated the effect of HT on bone loss [30, 33, 37]. Two studies included the time frame of DXA screening post-RRSO (6.3 years [33] and 1.25 years [30]). HT users had less bone loss compared to nonusers in 2 studies [33, 37].

\section{Discussion}

In our rigorously conducted systematic review, women with BRCA mutations who had RRSO had improvements in overall menopause-specific QOL with the use of HT, as well as reduction in vasomotor symptoms and VVA. The association of HT with breast cancer risk is still unclear due to the lack of long-term quality studies.

QOL after RRSO is an important consideration for women who elect to have RRSO. QOL in this population is comparable with the general population, [39, 40] though menopause-specific QOL may be compromised [34, 40-43]. Several studies show that HT improves menopause-specific QOL in symptomatic women who 


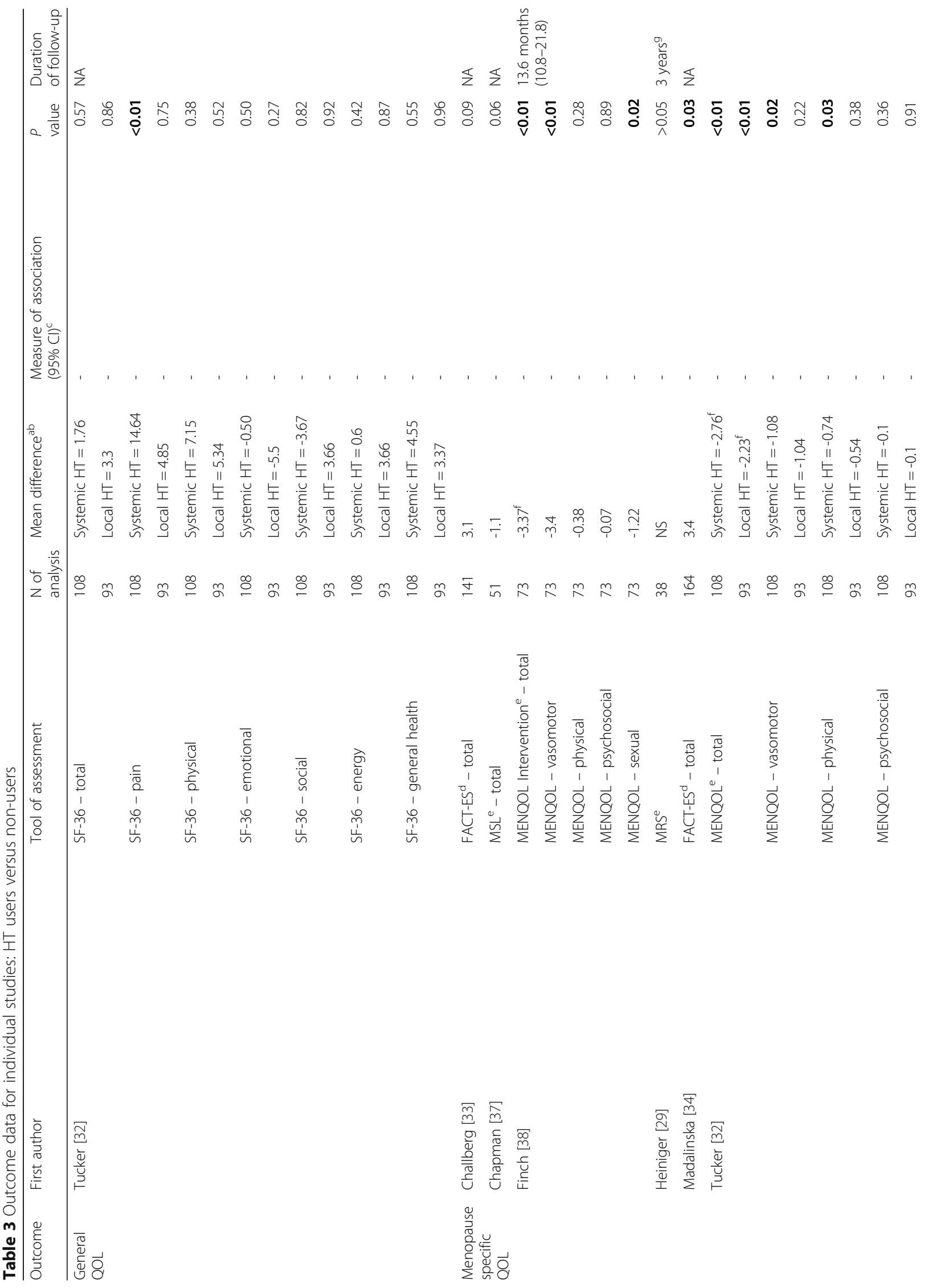




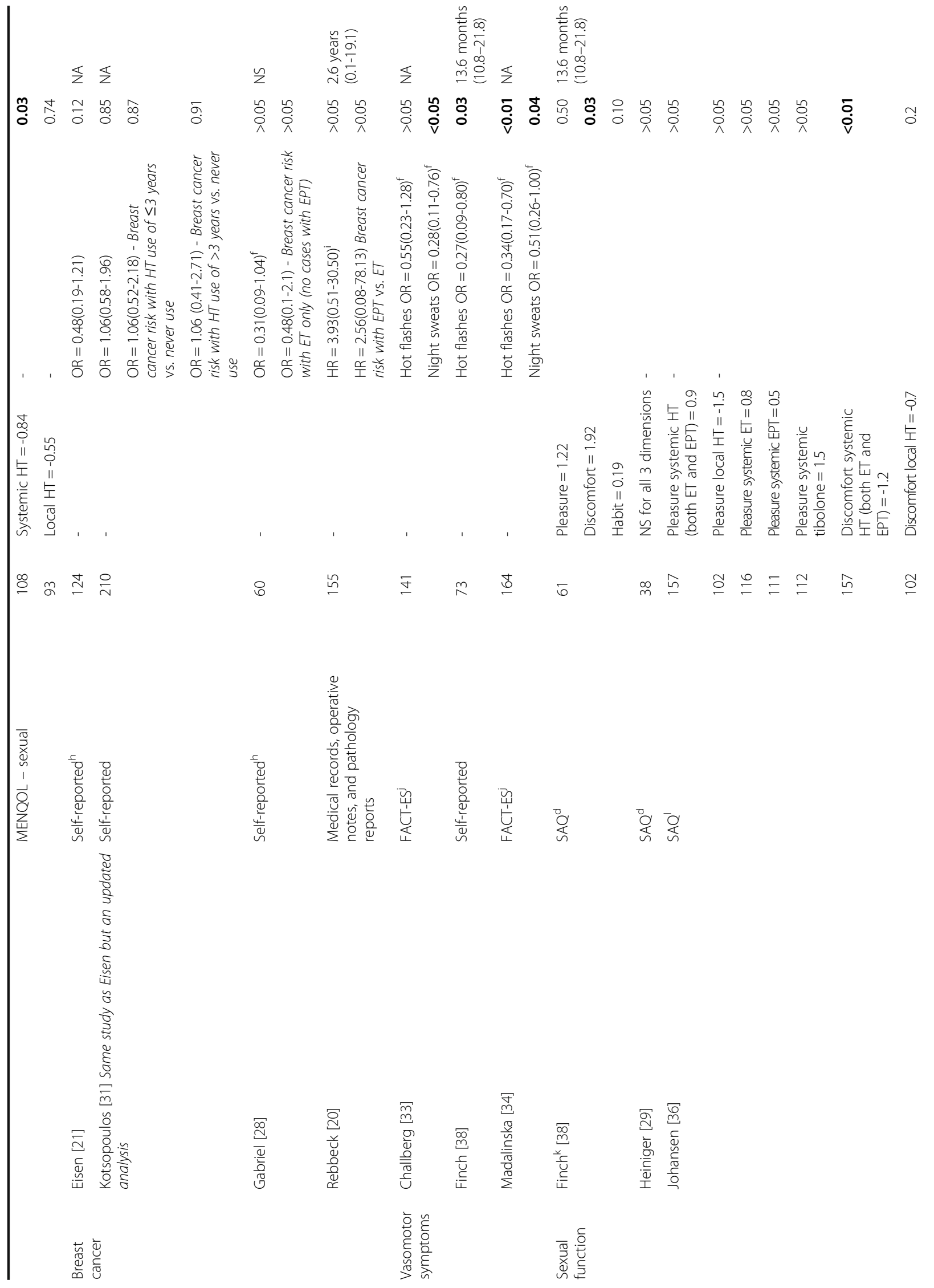




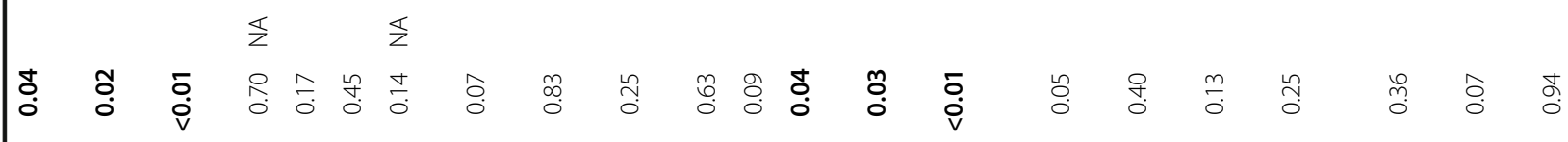

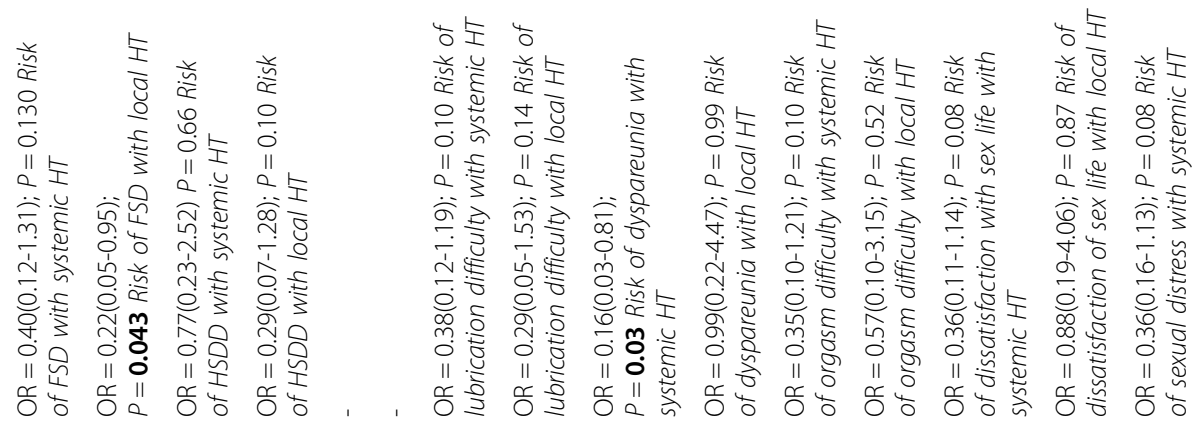

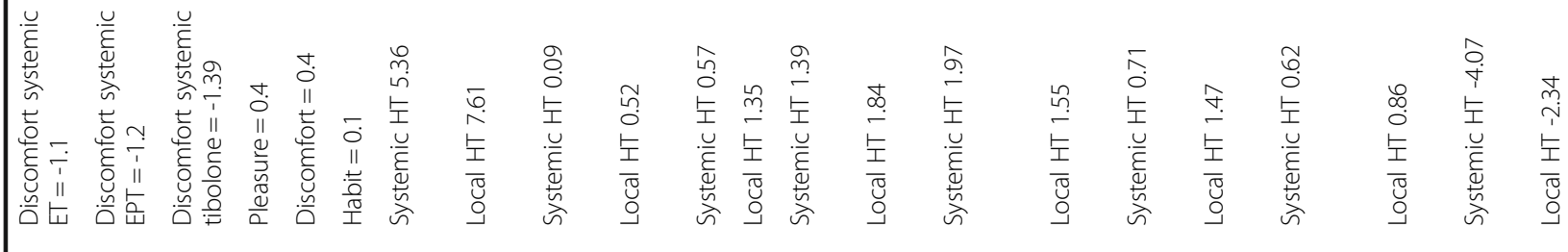

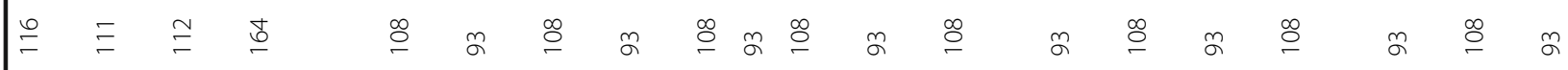




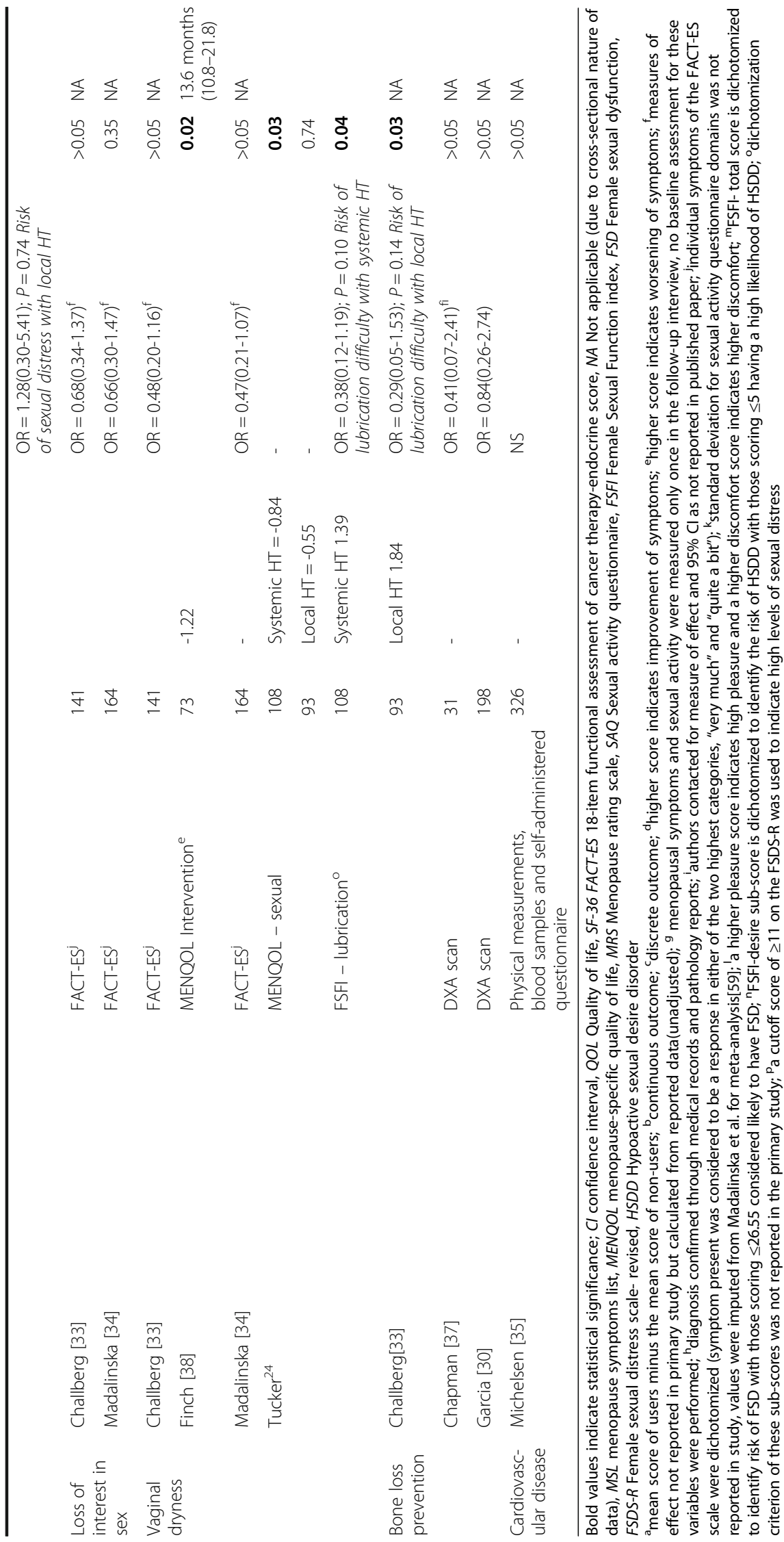


have gone through natural or surgical menopause [44-46]. Our cumulative results are consistent with these findings, as HT improved menopause-specific QOL following RRSO. Although 3 of the studies that assessed QOL showed no change with HT use, findings from these studies were more prone to bias due to confounding than studies that showed improvement in QOL [29, 33, 37].

The risk of breast cancer is the greatest concern women in the general population have when considering HT [47, 48]. This fear stems from the results of the WHI, which showed an increased risk of breast cancer in women on EPT for 5 or more years $[19,49]$. These results are often extrapolated to younger surgically menopausal women, even though the WHI participants mean age was 63 years at the time of study recruitment. In contrast, the use of ET alone in the WHI in younger women who have had a hysterectomy showed no increase in breast cancer risk $[19,50,51]$. Unfortunately we were unable to further explore the relative impact of ET versus EPT on breast cancer or other outcomes, as few studies reported the outcomes by specific treatment $[20,21]$ and not all specified the type of HT [29, 30, 35, 37].

Several recently published narrative reviews evaluated whether HT counteracts the breast cancer risk-reducing effects of RRSO [12, 22, 23, 52]. However, with newer evidence suggesting the lack of breast cancer riskreducing benefits from RRSO, the clinical inquiry that rather needs to be addressed is whether HT further increases the risk of breast cancer following a RRSO. These review papers concluded that HT seems to be safe in the short-term. We argue that given the scarcity and methodological limitations of the available evidence, no firm conclusions can be drawn, in the short or long term. None of the reviews critically appraised the included studies to assess their risk of bias. In our systematic review, we identified several limitations in the studies assessing breast cancer risk. All studies were affected by recall bias as HT was self-reported. Three of the studies were not designed to capture breast cancer incidence $[21,28,31]$. The only prospective study that captured this outcome had a relatively short follow-up (mean 2.6 years) [20], as well there was selection bias due to lost to follow-up [20]. Furthermore, in this study, breast cancer events within each group were relatively small which may have limited the estimate's precision and validity. Of note, all studies we identified were in women who had no personal history of breast cancer; we cannot comment on whether the results of our study could be applied to such women.

Among the other outcomes we studied, our systematic review found that HT was associated with a reduction in vasomotor symptoms. The benefits of $\mathrm{HT}$ on vasomotor symptoms is already well established [53]. VVA was also shown to improve with systemic HT in the pooled findings from the two relevant studies in our meta-analysis (Additional file 3). This aligns with established evidence in the literature [54]. However, in the individual studies, there was no significant improvement in VVA with HT. Unfortunately information on vaginal estrogen use was not provided in these studies. The one study that reported and evaluated the effect of vaginal estrogen use on vaginal dryness showed a reduction in the severity of the symptom and its risk [32]. Sexual discomfort improved for women taking systemic or local HT, while other sexual dimensions were not found to be significantly different between groups [32, 36, 38]. Sexual function is more complex than hormone levels alone, and other factors such as emotional satisfaction, psychological status, physical health and relationship status also need to be considered [55]. Androgen levels are reduced in surgical menopause [56], and may contribute to low libido $[57,58]$. However, in the studies that looked at sexual function in our review, only one study analyzed the effect of androgen levels on sexual desire and arousal and found no association [32]. The effect of testosterone on sexual function was outside the scope of this review.

There are several limitations associated with our study, mainly related to the limitations of the included studies. First, all of the studies included in this review were observational with a small sample size. Evidence from these studies cannot be considered as robust as those from RCTs. Second, very few studies provided sufficient outcome data suitable for meta-analysis limiting the value of these analyses (Additional file 3). Third, several studies in this review did not control for the effect of baseline QOL score and menopause status at the time of RRSO which are considered confounders. The only study that controlled for baseline score showed a significant improvement in QOL with HT [38]. Fourth, we could not assess the effect of HT regimens (ET vs. EPT) on different outcomes as these were poorly reported in most studies. Conclusions from our systematic review may also be affected by publication bias. The preferential publication of studies, with statistically significant treatment effects, may overestimate the effect of HT. Our search strategy aimed to locate both published and unpublished work. We were unable to locate any unpublished efforts.

Despite the limitations, our systematic review possesses several strengths that differentiate it from previous lessstructured reviews on this topic [12, 22, 23]. Our review was executed in compliance with MOOSE guidelines (Additional file 5) and based on a pre-specified protocol (PROSPERO registration number: 42014012997). We believe that the rigorous protocol and clear description of our method allow clinicians and RRSO patients to be confident that our findings are as rigorous as they can be based on the relative paucity of good evidence to answer the important questions that RRSO patients are asking. 


\section{Conclusion}

Cumulative evidence from our review highlights the benefits of HT in improving QOL and managing common menopausal symptoms induced by RRSO. However, no conclusions can be drawn about the safety of HT, as far as breast cancer risk is concerned. There are too few welldesigned long-term studies to draw firm conclusions to guide women and their clinicians in their decision-making about HT. Future well-designed RCTs are needed. In the absence of clear evidence to inform the use of HT post RRSO, clinicians and patients must carefully discuss the potential benefits of HT as well as non-hormonal therapies in improving QOL, in the context of the unknown risk of breast cancer in this population. However, this may not be of concern for women who opt for risk-reducing bilateral mastectomy since the risk of breast cancer in this population is negligible.

\section{Additional files}

Additional file 1: A Search Strategy for Electronic Bibliographic Databases. The document provides a detailed account of the search strategy implemented by an expert searcher (SC) in a variety of electronic databases including MEDLINE, EMBASE, CINAHL, Proquest Dissertations and Theses, SCOPUS, LILACS, PsycINFO, and Cochrane Library. The search was initially performed in February/ March 2014 and updated in March 2016. (DOCX 354 kb)

Additional file 2: A Search Strategy for Grey Literature: An Update. The document provides an update of the grey literature search performed in July, 2016, on SCOPUS, Proquest Dissertations and Theses, Clinical trial registries, Web of Science, and Google Scholar. (DOCX 22 kb)

Additional file 3: The Effect of Hormone Therapy on Quality of Life and Breast Cancer Risk After Risk-Reducing Salpingo-oophorectomy: Metaanalyses of Pooled studies. The document provides a written description of the methods and the results of the meta-analyses conducted in our study. (DOCX $39 \mathrm{~kb})$

Additional file 4: The results of full-text screening of eligible articles and the reason for exclusion whenever this may apply. (DOCX $19 \mathrm{~kb}$ )

Additional file 5: A Checklist summarizing compliance with MOOSE guidelines. The attached document is a checklist highlighting the compliance of our systematic review with the quality criteria specified by MOOSE guidelines. (DOC $27 \mathrm{~kb}$ )

\section{Abbreviations \\ BMI: Body mass index; EPT: Estrogen-progestogen therapy; ET: Estrogen therapy; FACT-ES: Functional Assessment of cancer therapy - endocrine score; FSD: Female sexual dysfunction; FSDS-R: Female sexual distress scale- revised; FSFI: Female sexual function index; HR: Hazard ratio; \\ HSDD: Hypoactive sexual desire disorder; HT: Hormone therapy; MENQOL- I: Menopause-specific quality of life - intervention; MRS: Menopause rating scale; MSL: Menopause symptoms list; OR: Odds ratio; QOL: Quality of life; RCTs: Randomized controlled trials; RRSO: Risk-reducing salpingo- oophorectomy; SAQ: Sexual activity questionnaire; SF-36: Short-form health survey; WA: Vulvovaginal atrophy; WHI: Women's health initiative}

\section{Acknowledgments}

We would like to acknowledge with much appreciation the role of Arianne Bayot, BScPharm, in this project which involved abstracting data from primary studies for data synthesis. We also would like to thank the authors of primary studies included in the review who responded to our requests for additional study data.

\section{Funding}

The study was not supported by any funding. DTE is supported by a Population Health Investigator Award from Alberta Innovates Health Solutions and holds a Canada Research Chair.

\section{Availability of data and material}

Datasets produced and/or analyzed during the current study is presented in the main paper or as additional supporting files.

\section{Authors' contributions}

TS: Study concept and design, acquisition of data, analysis and interpretation of data, drafting of the manuscript, critical revision of the manuscript for important intellectual content, statistical analysis, administrative, technical or material support, approval of final version, and accountable for accuracy and integrity of the work. SR: Study concept and design, interpretation of data, critical revision of the manuscript for important intellectual content, study supervision, approval of final version, and accountable for accuracy and integrity of the work. SC: Study concept and design, acquisition of data, critical revision of the manuscript for important intellectual content, technical or material support, and approval of final version. DTE: Analysis and interpretation of data, critical revision of the manuscript for important intellectual content, and approval of final version. NY: Study concept and design, acquisition of data, analysis and interpretation of data, drafting of the manuscript, critical revision of the manuscript for important intellectual content, and administrative, technical or material support, study supervision, approval of final version, and accountable for accuracy and integrity of the work.

\section{Competing interests}

The authors declare that they have no competing interests. NY has provided continuing education and/or participated in Advisory Boards/Consult Meetings for Warner-Chillcott, Teva and Pfizer Canada.

\section{Consent for publication}

Not applicable for this study.

\section{Ethics approval and consent to participate}

Not applicable for this study. This article does not contain any studies with human participants or animals performed by any of the authors.

\section{Publisher's Note}

Springer Nature remains neutral with regard to jurisdictional claims in published maps and institutional affiliations.

\section{Author details}

${ }^{1}$ Faculty of Pharmacy and Pharmaceutical Sciences, University of Alberta, Edmonton, AB T6G 1C9, Canada. ${ }^{2}$ Cavarzan Chair in Mature Women's Health Research, Department of Obstetrics and Gynecology, Rm 5 S131 Lois Hole Hospital/Robbins Pavilion Royal Alexandra Hospital, 10240 Kingsway Ave, Edmonton, AB T5H 3V9, Canada. ${ }^{3} 2$ K4.01 WC Mackenzie Health Science Center, University of Alberta, Edmonton, AB T6G 2R7, Canada. ${ }^{4}$ School of Public Health, 2-040 Li Ka Shing HRIF, University of Alberta, Edmonton, AB T6G 2E1, Canada.

Received: 8 October 2016 Accepted: 3 March 2017

Published online: 21 March 2017

\section{References}

1. Hartmann LC, Lindor NM. The role of risk-reducing surgery in hereditary breast and ovarian cancer. N Engl J Med. 2016;374(5):454-68.

2. Antoniou AC, Cunningham AP, Peto J, Evans DG, Lalloo F, Narod SA, Risch HA, Eyfjord JE, Hopper JL, Southey MC, et al. The BOADICEA model of genetic susceptibility to breast and ovarian cancers: updates and extensions. Br J Cancer. 2008;98(8):1457-66.

3. Mavaddat N, Peock S, Frost D, Ellis S, Platte R, Fineberg E, Evans DG, Izatt L, Eeles RA, Adlard J, et al. Cancer risks for BRCA1 and BRCA2 mutation carriers: results from prospective analysis of EMBRACE. J Natl Cancer Inst. 2013:105(11):812-22.

4. Brohet RM, Velthuizen ME, Hogervorst FB, Meijers-Heijboer HE, Seynaeve C, Collee MJ, Verhoef S, Ausems MG, Hoogerbrugge N, van Asperen CJ, et al. Breast and ovarian cancer risks in a large series of clinically ascertained 
families with a high proportion of BRCA1 and BRCA2 Dutch founder mutations. J Med Genet. 2014;51(2):98-107.

5. Rebbeck TR, Kauff ND, Domchek SM. Meta-analysis of risk reduction estimates associated with risk-reducing salpingo-oophorectomy in BRCA1 or BRCA2 mutation carriers. J Natl Cancer Inst. 2009;101(2):80-7.

6. Kotsopoulos J, Huzarski T, Gronwald J, Singer CF, Moller P, Lynch HT, Armel S, Karlan B, Foulkes WD, Neuhausen SL, et al. Bilateral oophorectomy and breast cancer risk in BRCA1 and BRCA2 mutation carriers. J Natl Cancer Inst. 2017;109:1.

7. Heemskerk-Gerritsen BA, Seynaeve C, van Asperen CJ, Ausems MG, Collee JM, van Doorn HC, Gomez Garcia EB, Kets CM, van Leeuwen FE, Meijers-Heijboer $\mathrm{HE}$, et al. Breast cancer risk after salpingo-oophorectomy in healthy BRCA1/2 mutation carriers: revisiting the evidence for risk reduction. J Natl Cancer Inst. 2015:107:5.

8. Walker JL, Powell CB, Chen LM, Carter J, Bae Jump VL, Parker LP, Borowsky ME, Gibb RK. Society of gynecologic oncology recommendations for the prevention of ovarian cancer. Cancer. 2015;121(13):2108-20.

9. Paluch-Shimon S, Cardoso F, Sessa C, Balmana J, Cardoso MJ, Gilbert F, Senkus E. Prevention and screening in BRCA mutation carriers and other breast/ ovarian hereditary cancer syndromes: ESMO Clinical Practice Guidelines for cancer prevention and screening. Ann Oncol. 2016;27 suppl 5:v103-10.

10. Daly MB, Pilarski R, Axilbund JE, Berry M, Buys SS, Crawford B, Farmer M, Friedman S, Garber JE, Khan S, et al. Genetic/Familial High-Risk Assessment: Breast and Ovarian, Version 2.2015. J Natl Compr Canc Netw. 2016;14(2):153-62.

11. Daly MB, Axilbund JE, Buys S, Crawford B, Farrell CD, Friedman S, Garber JE, Goorha S, Gruber SB, Hampel H, et al. Genetic/familial high-risk assessment: breast and ovarian. J Natl Compr Canc Netw. 2010;8(5):562-94.

12. Finch A, Narod SA. Quality of life and health status after prophylactic salpingo-oophorectomy in women who carry a BRCA mutation: A review. Maturitas. 2011;70(3):261-5.

13. Gallagher JC. Effect of early menopause on bone mineral density and fractures. Menopause. 2007;14(3 Pt 2):567-71.

14. Parker WH, Broder MS, Chang E, Feskanich D, Farquhar C, Liu Z, Shoupe D, Berek JS, Hankinson S, Manson JE. Ovarian conservation at the time of hysterectomy and long-term health outcomes in the nurses' health study. Obstet Gynecol. 2009;113(5):1027-37.

15. Rocca WA, Grossardt BR, Shuster LT. Oophorectomy, estrogen, and dementia: a 2014 update. Mol Cell Endocrinol. 2014;389(1-2):7-12.

16. Gass ML, Heights M, Manson JE, Cosman F, Hayes H, Grodstein F, Lab C, Jordan V, Karas RH, Kaunitz AM, Maki PM, Schmidt PJ, Shifren JL, Stuenkel CA, Utian WH, Wisch KJ, Bilancini AM, Clarkson TB, Gass ML, Heights M, Goldstein SR, Kagan R, Kaunitz AM, Maki PM, Manson JE, Pace DT, Schiff I, Meigs JV, Obstetrics V, Schnatz PF, Shapiro M, Shifren JL, Obstetrics V, Sievert LL, Utian WH, Warren MP. The 2012 hormone therapy position statement of: The North American Menopause Society. Menopause. 2012;19(3):257-71.

17. Reid R, Abramson BL, Blake J, Desindes S, Dodin S, Johnston S, Rowe T, Sodhi N, Wilks P, Wolfman W, et al. Managing menopause. J Obstet Gynaecol Can. 2014;36(9):830-8.

18. de Villiers TJ, Gass ML, Haines CJ, Hall JE, Lobo RA, Pierroz DD, Rees M. Global Consensus Statement on menopausal hormone therapy. Maturitas. 2013;74(4):391-2.

19. Manson JE, Chlebowski RT, Stefanick ML, Aragaki AK, Rossouw JE, Prentice RL, Anderson G, Howard BV, Thomson CA, LaCroix AZ, et al. Menopausal hormone therapy and health outcomes during the intervention and extended poststopping phases of the Women's Health Initiative randomized trials. JAMA. 2013;310(13):1353-68.

20. Rebbeck TR, Friebel T, Wagner T, Lynch HT, Garber JE, Daly MB, Isaacs $C$, Olopade Ol, Neuhausen SL, Van't V, et al. Effect of short-term hormone replacement therapy on breast cancer risk reduction after bilateral prophylactic oophorectomy in BRCA1 and BRCA2 mutation carriers: the PROSE Study Group. J Clin Oncol. 2005;23(31):7804-10.

21. Eisen A, Lubinski J, Gronwald J, Moller P, Lynch HT, Klijn J, Kim-Sing C, Neuhausen SL, Gilbert L, Ghadirian P, et al. Hormone therapy and the risk of breast cancer in BRCA1 mutation carriers. J Natl Cancer Inst. 2008;100(19):1361-7.

22. Marchetti C, ladarola R, Palaia I, di Donato V, Perniola G, Muzii L, Panici PB. Hormone therapy in oophorectomized BRCA1/2 mutation carriers. Menopause. 2014;21(7):763-8.

23. Birrer N, Chinchilla C, Del Carmen M, Dizon DS. Is Hormone Replacement Therapy Safe in Women With a BRCA Mutation?: A Systematic Review of the Contemporary Literature. Am J Clin Oncol. 2016. doi:10.1097/COC. 0000000000000269 .
24. Stroup DF, Berlin JA, Morton SC, Olkin I, Williamson GD, Rennie D, Moher D, Becker BJ, Sipe TA, Thacker SB. Meta-analysis of observational studies in epidemiology: a proposal for reporting. Meta-analysis Of Observational Studies in Epidemiology (MOOSE) group. JAMA. 2000;283(15):2008-12.

25. Jadad AR, Moore RA, Carroll D, Jenkinson C, Reynolds DJ, Gavaghan DJ, McQuay HJ. Assessing the quality of reports of randomized clinical trials: is blinding necessary? Control Clin Trials. 1996;17(1):1-12.

26. Nolan JP, Hazinski MF, Billi JE, Boettiger BW, Bossaert L, de Caen AR, Deakin CD, Drajer S, Eigel B, Hickey RW, et al. Part 1: Executive summary: 2010 International Consensus on Cardiopulmonary Resuscitation and Emergency Cardiovascular Care Science with Treatment Recommendations. Resuscitation. 2010;2010(81 Suppl 1):e1-25.

27. Myung SK, Ju W, McDonnell DD, Lee YJ, Kazinets G, Cheng CT, Moskowitz JM. Mobile phone use and risk of tumors: a meta-analysis. J Clin Oncol. 2009;27(33):5565-72.

28. Gabriel CA, Tigges-Cardwell J, Stopfer J, Erlichman J, Nathanson K, Domchek SM. Use of total abdominal hysterectomy and hormone replacement therapy in BRCA1 and BRCA2 mutation carriers undergoing risk-reducing salpingo-oophorectomy. Fam Cancer. 2009;8(1):23-8.

29. Heiniger L, Butow PN, Coll J, Bullen T, Wilson J, Baylock B, Meiser B, Price MA. Long-term outcomes of risk-reducing surgery in unaffected women at increased familial risk of breast and/or ovarian cancer. Fam Cancer. 2015;14(1):105-15.

30. Garcia C, Lyon L, Conell C, Littell RD, Powell CB. Osteoporosis risk and management in BRCA1 and BRCA2 carriers who undergo risk-reducing salpingo-oophorectomy. Gynecol Oncol. 2015;138(3):723-6.

31. Kotsopoulos J, Huzarski T, Gronwald J, Moller P, Lynch HT, Neuhausen SL, Senter L, Demsky R, Foulkes WD, Eng C, et al. Hormone replacement therapy after menopause and risk of breast cancer in BRCA1 mutation carriers: a case-control study. Breast Cancer Res Treat. 2016;155(2):365-73.

32. Tucker PE, Bulsara MK, Salfinger SG, Tan JJ, Green H, Cohen PA. The effects of pre-operative menopausal status and hormone replacement therapy (HRT) on sexuality and quality of life after risk-reducing salpingo-oophorectomy. Maturitas. 2016;85:42-8.

33. Challberg J, Ashcroft L, Lalloo F, Eckersley B, Clayton R, Hopwood P, Selby P, Howell A, Evans DG. Menopausal symptoms and bone health in women undertaking risk reducing bilateral salpingo-oophorectomy: significant bone health issues in those not taking HRT. Br J Cancer. 2011;105(1):22-7.

34. Madalinska JB, van Beurden M, Bleiker EM, Valdimarsdottir HB, Hollenstein J, Massuger LF, Gaarenstroom KN, Mourits MJ, Verheijen RH, van Dorst EB, et al. The impact of hormone replacement therapy on menopausal symptoms in younger high-risk women after prophylactic salpingooophorectomy. J Clin Oncol. 2006;24(22):3576-82.

35. Michelsen TM, Tonstad S, Pripp AH, Trope CG, Dorum A. Coronary heart disease risk profile in women who underwent salpingo-oophorectomy to prevent hereditary breast ovarian cancer. Int J Gynecol Cancer. 2010; 20(2):233-9.

36. Johansen N, Liavaag AH, Tanbo TG, Dahl AA, Pripp AH, Michelsen TM. Sexual activity and functioning after risk-reducing salpingo-oophorectomy: Impact of hormone replacement therapy. Gynecol Oncol. 2016;140(1):101-6.

37. Chapman JS, Powell CB, McLennan J, Crawford B, Mak J, Stewart N, Chen LM. Surveillance of survivors: follow-up after risk-reducing salpingo-oophorectomy in BRCA 1/2 mutation carriers. Gynecol Oncol. 2011;122(2):339-43.

38. Finch A, Metcalfe KA, Chiang JK, Elit L, McLaughlin J, Springate C, Demsky R, Murphy J, Rosen B, Narod SA. The impact of prophylactic salpingooophorectomy on menopausal symptoms and sexual function in women who carry a BRCA mutation. Gynecol Oncol. 2011;121(1):163-8.

39. Elit L, Charles C, Gold I, Gafni A, Farrell S, Tedford S, Dal Bello D, Whelan T. Women's perceptions about treatment decision making for ovarian cancer. Gynecol Oncol. 2003;88(2):89-95.

40. Robson M, Hensley M, Barakat R, Brown C, Chi D, Poynor E, Offit K. Quality of life in women at risk for ovarian cancer who have undergone riskreducing oophorectomy. Gynecol Oncol. 2003;89(2):281-7.

41. Elit L, Esplen MJ, Butler K, Narod S. Quality of life and psychosexual adjustment after prophylactic oophorectomy for a family history of ovarian cancer. Fam Cancer. 2001;1(3-4):149-56.

42. Madalinska JB, Hollenstein J, Bleiker E, van Beurden M, Valdimarsdottir HB, Massuger LF, Gaarenstroom KN, Mourits MJ, Verheijen RH, van Dorst EB, et al. Quality-of-life effects of prophylactic salpingo-oophorectomy versus gynecologic screening among women at increased risk of hereditary ovarian cancer. J Clin Oncol. 2005;23(28):6890-8. 
43. Ozdemir S, Celik C, Gorkemli H, Kiyici A, Kaya B. Compared effects of surgical and natural menopause on climacteric symptoms, osteoporosis, and metabolic syndrome. Int J Gynaecol Obstet. 2009;106(1):57-61.

44. Limouzin-Lamothe MA, Mairon N, Joyce CR, Le Gal M. Quality of life after the menopause: influence of hormonal replacement therapy. Am J Obstet Gynecol. 1994;170(2):618-24.

45. Kotz K, Alexander JL, Dennerstein L. Estrogen and androgen hormone therapy and well-being in surgically postmenopausal women. J Womens Health (Larchmt). 2006;15(8):898-908.

46. Buzgova R, Kaniokova J. The influence of hormone replacement therapy on the quality of life of women in menopause. Ceska Gynekol. 2013;78(5):420-6.

47. Zimmerman VL, Smeltzer SC. Hormone therapy and breast cancer. Clin Excell Nurse Pract. 2000;4(1):30-4.

48. Gerend MA, Aiken LS, Erchull MJ, Lapin A. Women's use of hormone therapy before and after the Women's Health Initiative: a psychosocial model of stability and change. Prev Med. 2006;43(3):158-64.

49. Rossouw JE, Anderson GL, Prentice RL, LaCroix AZ, Kooperberg C, Stefanick ML, Jackson RD, Beresford SA, Howard BV, Johnson KC, et al. Risks and benefits of estrogen plus progestin in healthy postmenopausal women: principal results From the Women's Health Initiative randomized controlled trial. JAMA. 2002;288(3):321-33.

50. Stefanick ML, Anderson GL, Margolis KL, Hendrix SL, Rodabough RJ, Paskett ED, Lane DS, Hubbell FA, Assaf AR, Sarto GE, et al. Effects of conjugated equine estrogens on breast cancer and mammography screening in postmenopausal women with hysterectomy. JAMA. 2006; 295(14):1647-57.

51. Beral V. Breast cancer and hormone-replacement therapy in the Million Women Study. Lancet. 2003;362(9382):419-27.

52. Guidozzi F. Hormone therapy after prophylactic risk-reducing bilateral salpingo-oophorectomy in women who have BRCA gene mutation. Climacteric. 2016;1-4.

53. Maclennan AH, Broadbent JL, Lester S, Moore V. Oral oestrogen and combined oestrogen/progestogen therapy versus placebo for hot flushes. Cochrane Database Syst Rev. 2004;4, CD002978.

54. Suckling J, Lethaby A, Kennedy R. Local oestrogen for vaginal atrophy in postmenopausal women. Cochrane Database Syst Rev. 2006;:CD001500

55. Dennerstein L, Alexander JL, Kotz K. The menopause and sexual functioning: a review of the population-based studies. Annu Rev Sex Res. 2003;14:64-82.

56. Hughes Jr CL, Wall LL, Creasman WT. Reproductive hormone levels in gynecologic oncology patients undergoing surgical castration after spontaneous menopause. Gynecol Oncol. 1991:40(1):42-5.

57. Shifren JL. Androgen deficiency in the oophorectomized woman. Fertil Steril. 2002;77 Suppl 4:S60-62.

58. Sherwin BB, Gelfand MM. The role of androgen in the maintenance of sexual functioning in oophorectomized women. Psychosom Med. 1987; 49(4):397-409.

59. Higgins JPT, Green S. Cochrane Collaboration.: Cochrane handbook for systematic reviews of interventions. Chichester, England. Hoboken: Wiley-Blackwell; 2008.

\section{Submit your next manuscript to BioMed Central and we will help you at every step:}

- We accept pre-submission inquiries

- Our selector tool helps you to find the most relevant journal

- We provide round the clock customer support

- Convenient online submission

- Thorough peer review

- Inclusion in PubMed and all major indexing services

- Maximum visibility for your research

Submit your manuscript at www.biomedcentral.com/submit

Biomed Central 